\title{
Lattice parameters and Raman-active phonon modes of $\beta-\left(\mathrm{Al}_{\mathbf{x}} \mathrm{Ga}_{1-\mathrm{x}}\right)_{2} \mathrm{O}_{3}$
}

Christian Kranert, Marcus Jenderka, Jörg Lenzner, Michael Lorenz, Holger von Wenckstern, Rüdiger SchmidtGrund, and Marius Grundmann

Citation: Journal of Applied Physics 117, 125703 (2015); doi: 10.1063/1.4915627

View online: https://doi.org/10.1063/1.4915627

View Table of Contents: http://aip.scitation.org/toc/jap/117/12

Published by the American Institute of Physics

\section{Articles you may be interested in}

Wide bandgap engineering of $(\mathrm{AlGa})_{2} \mathrm{O}_{3}$ films

Applied Physics Letters 105, 162107 (2014); 10.1063/1.4900522

Dielectric function in the spectral range $(0.5-8.5) \mathrm{eV}$ of an $\left(\mathrm{Al}_{\mathrm{X}} \mathrm{Ga}_{1-\chi}\right)_{2} \mathrm{O}_{3}$ thin film with continuous composition spread

Journal of Applied Physics 117, 165307 (2015); 10.1063/1.4919088

Modulation-doped $\beta$-( $\left.\mathrm{Al}_{0.2} \mathrm{Ga}_{0.8}\right)_{2} \mathrm{O}_{3} / \mathrm{Ga}_{2} \mathrm{O}_{3}$ field-effect transistor

Applied Physics Letters 111, 023502 (2017); 10.1063/1.4993569

$\beta-\left(\mathrm{Al}_{\mathrm{X}} \mathrm{Ga}_{1-\mathrm{x}}\right)_{2} \mathrm{O}_{3} / \mathrm{Ga}_{2} \mathrm{O}_{3}(010)$ heterostructures grown on $\beta-\mathrm{Ga}_{2} \mathrm{O}_{3}(010)$ substrates by plasma-assisted molecular beam epitaxy

Journal of Vacuum Science \& Technology A: Vacuum, Surfaces, and Films 33, 041508 (2015);

$10.1116 / 1.4922340$

Crystal Structure of $\beta-\mathrm{Ga}_{2} \mathrm{O}_{3}$

The Journal of Chemical Physics 33, 676 (1960); 10.1063/1.1731237

Epitaxial growth of phase-pure $\varepsilon-\mathrm{Ga}_{2} \mathrm{O}_{3}$ by halide vapor phase epitaxy

Journal of Applied Physics 118, 085301 (2015); 10.1063/1.4929417

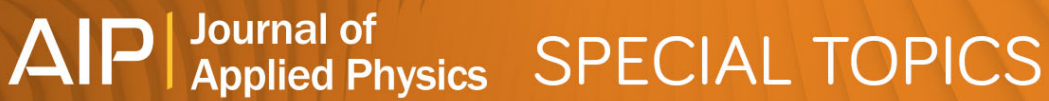

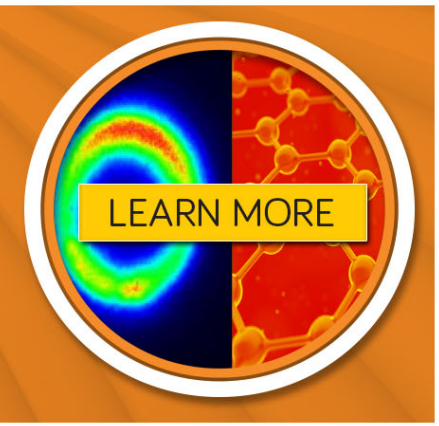




\title{
Lattice parameters and Raman-active phonon modes of $\beta-\left(\mathrm{Al}_{x} \mathrm{Ga}_{1-x}\right)_{2} \mathrm{O}_{3}$
}

\author{
Christian Kranert, ${ }^{\text {a) }}$ Marcus Jenderka, Jörg Lenzner, Michael Lorenz, \\ Holger von Wenckstern, Rüdiger Schmidt-Grund, and Marius Grundmann \\ Institut für Experimentelle Physik II, Universität Leipzig, Halbleiterphysik, Linnéstr. 5, 04103 Leipzig, \\ Germany
}

(Received 20 December 2014; accepted 9 March 2015; published online 23 March 2015)

\begin{abstract}
We present X-ray diffraction and Raman spectroscopy investigations of a (100)-oriented $\left(\mathrm{Al}_{x} \mathrm{Ga}_{1-x}\right)_{2} \mathrm{O}_{3}$ thin film on $\mathrm{MgO}(100)$ and bulk-like ceramics in dependence on their composition. The thin film grown by pulsed laser deposition has a continuous lateral composition spread allowing to determine precisely the dependence of the phonon mode properties and lattice parameters on the chemical composition. For $x<0.4$, we observe the single-phase $\beta$-modification. Its lattice parameters and phonon energies depend linearly on the composition. We determined the slopes of these dependencies for the individual lattice parameters and for nine Raman lines, respectively. While the lattice parameters of the ceramics follow Vegard's rule, deviations are observed for the thin film. This deviation has only a small effect on the phonon energies, which show a reasonably good agreement between thin film and ceramics. (C) 2015 AIP Publishing LLC.
\end{abstract}

[http://dx.doi.org/10.1063/1.4915627]

\section{INTRODUCTION}

The large band gap of gallium oxide $\mathrm{Ga}_{2} \mathrm{O}_{3}$ of approximately $5 \mathrm{eV}$ motivates its use in applications like high-power devices $^{1}$ and ultraviolet (UV) photodetectors ${ }^{2-5}$ or other deep UV optoelectronics. For carrier confinement in heterostructures or quantum wells, for example, a material with an even larger band gap is required. Alloying with $\mathrm{Al}_{2} \mathrm{O}_{3}$ increases the band gap and can, therefore, be expected to be a well-suited barrier material.

For the application of the ternary $\left(\mathrm{Al}_{x} \mathrm{Ga}_{1-x}\right)_{2} \mathrm{O}_{3}$ alloy, its fundamental properties need to be known. Particularly, for the $\left(\mathrm{Al}_{x} \mathrm{Ga}_{1-x}\right)_{2} \mathrm{O}_{3}$ compound, structural changes throughout the composition range are inevitable owing to the different crystal structures of monoclinic $\beta-\mathrm{Ga}_{2} \mathrm{O}_{3}$ and trigonal $\alpha-\mathrm{Al}_{2} \mathrm{O}_{3}$. In previous studies, different upper limits for the incorporation of $\mathrm{Al}$ atoms into the $\beta-\mathrm{Ga}_{2} \mathrm{O}_{3}$ lattice from 50 at. \% (Ref. 6) over 67 at. \% (Ref. 7) to around 80 at. \% for powder samples ${ }^{8,9}$ and of approximately 60 at. $\%$ for thin film samples ${ }^{10}$ were found. Although the structural properties of the powder samples were studied by means of X-ray diffraction (XRD) ${ }^{7-9}$ the dependence of the individual lattice parameters on the composition was not yet analyzed.

Additionally to XRD, Raman scattering spectroscopy is well suited for the investigation of such structural changes due to its sensitivity to symmetry properties. Further, in case of a solid solution without secondary phases, the variation of the phonon energy with the composition can be used to determine the composition from the Raman spectra as recently investigated for $(\mathrm{In}, \mathrm{Ga})_{2} \mathrm{O}_{3} \cdot{ }^{11}$ However, no results on Raman scattering measurements of $\left(\mathrm{Al}_{x} \mathrm{Ga}_{1-x}\right)_{2} \mathrm{O}_{3}$ samples have been published so far.

Here, we present a combined XRD and Raman scattering study on a 2-in. in diameter thin film with a continuous composition spread (CCS) in comparison to bulk-like

\footnotetext{
${ }^{a)}$ Electronic mail: christian.kranert@uni-leipzig.de
}

ceramic samples. For the composition range, for which the ceramic materials exclusively exhibit the $\beta$-modification, we obtain the individual lattice parameters as a function of the composition in compliance with Vegard's rule. We further derive the phonon energy dependencies on the composition from the Raman measurements. The use of the CCS approach for the thin film allows us to determine the film's properties for virtually any composition within its composition range. Based on these comprehensive data sets, we compare the properties of the thin film with those of the bulk-like ceramics.

\section{EXPERIMENTAL SETUP AND SAMPLES}

The $\left(\mathrm{Al}_{x} \mathrm{Ga}_{1-x}\right)_{2} \mathrm{O}_{3}$ thin film studied here was grown by means of pulsed laser deposition (PLD) using a segmented PLD source target and exhibits a continuous composition spread. For further details on the applied CCS technique, please refer to von Wenckstern et al. ${ }^{12}$ The samples were prepared on a 2-in. wafer of $\mathrm{MgO}$ (100). An oxygen pressure in the PLD chamber of 0.08 mbar was chosen, and the substrate was heated to approximately $650^{\circ} \mathrm{C}$. The targets were ablated using a $\mathrm{KrF}$ excimer laser $(\lambda=248 \mathrm{~nm})$ with a pulse energy of $600 \mathrm{~nm}$ and a repetition rate of $15 \mathrm{~Hz}$. By applying 60000 laser pulses, a film thickness between $400 \mathrm{~nm}$ (Garich side) and $600 \mathrm{~nm}$ (Al-rich side) was obtained as determined by spectroscopic ellipsometry. A binary $\beta-\mathrm{Ga}_{2} \mathrm{O}_{3}$ thin film for comparison was deposited under the same conditions on a $(5 \times 5) \mathrm{mm}^{2}$ substrate.

We further compared these results to ceramic samples similar to the targets used for the PLD process. These were prepared by homogenization and pressing of $\mathrm{Ga}_{2} \mathrm{O}_{3}(5 \mathrm{~N}$ purity) and $\mathrm{Al}_{2} \mathrm{O}_{3}$ (4N5 purity) powders. Subsequently, they were sintered either for $48 \mathrm{~h}$ at $1400^{\circ} \mathrm{C}$ or for $15 \mathrm{~h}$ at $1550^{\circ} \mathrm{C}$. Longer sintering times did not change the properties of the $\beta$-phase material.

Raman scattering was excited by means of a HeCd laser emitting at $\lambda_{\mathrm{exc}}=325 \mathrm{~nm}$ and a diode-pumped solid state 
laser emitting at $\lambda_{\text {exc }}=532 \mathrm{~nm}$. The light was focused and collected by $50 \times$ microscope objectives (backscattering geometry) with a numerical aperture of 0.40 yielding a lateral resolution of approximately $2 \mu \mathrm{m}$. Within this spot size, the composition gradient of the CCS samples is negligibly small. The collected light was analyzed for its linear polarization using a Glan-Thompson prism. The spectra were recorded by a Jobin Yvon U1000 double spectrometer equipped with two gratings with 2400 lines $/ \mathrm{mm}$. We used a liquid nitrogen cooled charge coupled device with $2048 \times 512$ square pixels with an edge length of $13.5 \mu \mathrm{m}$ for detection. The spectral resolution was set to approximately $1 \mathrm{~cm}^{-1}$.

The thin film composition was determined by means of energy dispersive X-Ray analysis (EDX) from the relative intensities of the L-lines of $\mathrm{Ga}$ and the $\mathrm{K}$-lines of $\mathrm{Al}$. Diffraction patterns of the ceramic samples were measured using a Philips X'pert diffractometer with $\mathrm{Cu} \mathrm{K} \alpha$ radiation and Bragg-Brentano goniometer. Laterally resolved X-Ray diffraction patterns were recorded using a PANalytical X'pert MRD pro diffractometer with $\mathrm{Cu} \mathrm{K} \alpha$ radiation and a PIXcel ${ }^{3 \mathrm{D}}$ detector in 1D scanning mode with 255 channels. A programmable divergence slit yields an illuminated area of $1.5 \times 10 \mathrm{~mm}^{2}$. For the linescans, a step size of $1 \mathrm{~mm}$ was chosen.

\section{RESULTS}

\section{A. EDX}

The lateral variation of the composition of the thin film is shown in Fig. 1. A one-dimensional composition spread
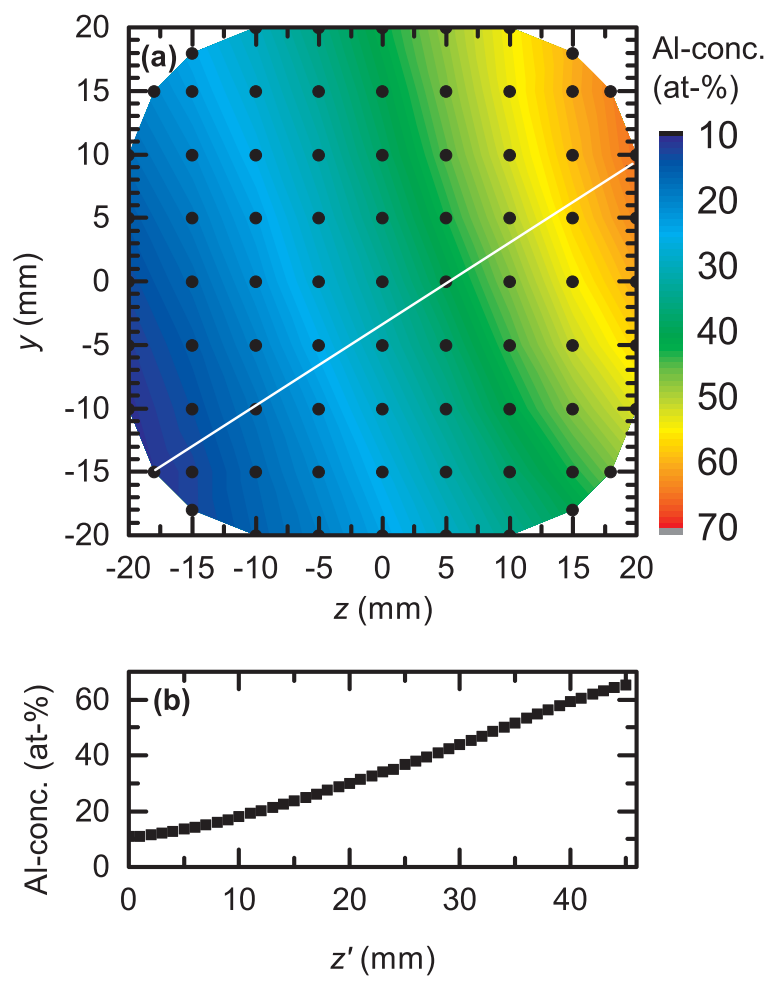

FIG. 1. Aluminum concentration of the $\left(\mathrm{Al}_{x} \mathrm{Ga}_{1-x}\right)_{2} \mathrm{O}_{3} \mathrm{CCS}$ thin film grown on $\mathrm{MgO}(100)$ as determined by EDX measurements. (a) Concentration mapping of the film. The black circles mark the spots where the concentration was actually measured. The false color image results from an interpolation between these points. Position $(0,0)$ is situated at the center of the 2-in. wafer. (b) Line scan of the same sample along the white line in (a). was obtained and we find that the variation of the $\mathrm{Al}$ content along the gradient has a slight $\mathrm{S}$-shape inline with prediction from simulations of the CCS PLD process. ${ }^{12}$ The Al concentration $x$ ranges from approximately 0.10 to 0.65 . Please note that $x$ always refers to the $\mathrm{Al}$ content on cation site while $y$ and $z$ are the spatial coordinates defining lateral positions on the thin film.

\section{B. XRD}

Sintering of the pressed powders at $T_{1}=1673 \mathrm{~K}$ $\left(1400^{\circ} \mathrm{C}\right)$ yielded white ceramic samples in the whole composition range under investigation $(0 \leq x \leq 0.69)$. The samples sintered at $T_{2}=1823 \mathrm{~K}\left(1550^{\circ} \mathrm{C}\right)$ also remained white for $x<0.4$, but became bluish for larger Al concentration. $\mathrm{X}$-ray powder diffraction measurements of these samples revealed single-phase $\beta$-type $\left(\mathrm{Al}_{x} \mathrm{Ga}_{1-x}\right)_{2} \mathrm{O}_{3}$ within the detection limit of approximately $1 \%$ for $x<0.4$ for both sintering temperatures. At higher $\mathrm{Al}$ concentrations, small amounts (around the detection limit of $1 \%$ for $0.4<x<0.55$ ) of additional $\alpha$-phase material were found for $T_{1}$ as a result of Rietveld refinement of the XRD patterns (see below). For higher $\mathrm{Al}$ content, the contribution of the $\alpha$-phase increases which was found to be the dominant phase for $x=0.69$. Sintering at $T_{2}$ yielded predominantly $\gamma-\left(\mathrm{Al}_{x} \mathrm{Ga}_{1-x}\right)_{2} \mathrm{O}_{3}$ for $x>0.4$ with a small amount of the $\beta$-phase.

The diffraction patterns of the ceramic samples were analyzed by means of Rietveld refinement ${ }^{13}$ using the PANalytical HighScore Plus 3.0.5 software to obtain the lattice parameters. For the $\beta$-phase, the values for binary $\beta-\mathrm{Ga}_{2} \mathrm{O}_{3}{ }^{14}$ were used as initial structure. The resulting lattice parameters are shown in Fig. 2. A good agreement is found between both sintering temperatures, indicating that the results are not influenced by the temperature and that the samples are well equilibrated. From a linear regression of the lattice parameters of the samples sintered at $T_{1}$, we obtain the dependencies of the lattice parameters, which are in agreement with Vegard's law, as follows: $a=(12.21-0.42 x) \AA, \quad b=(3.04-0.13 x) \AA$, $c=(5.81-0.17 x) \AA$, and, $\beta=(103.87+0.31 x)^{\circ}$. The data point at $x=0.38$ for sintering at $T_{2}$ shows an inconsistency to

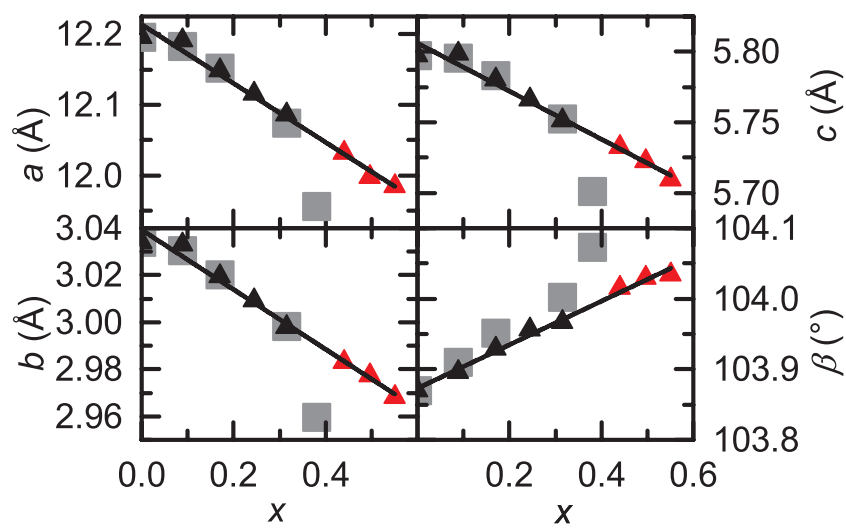

FIG. 2. Lattice parameters for ceramic $\left(\mathrm{Al}_{x} \mathrm{Ga}_{1-x}\right)_{2} \mathrm{O}_{3}$ samples in dependence on the Al concentration. Data points for the samples sintered at $T_{1}=1673 \mathrm{~K}$ and at $T_{2}=1823 \mathrm{~K}$ are shown as black and red triangles and as grey squares, respectively. The red color indicates samples which are not completely single-phase. The black lines result from a linear regression of all data points from samples sintered at $T_{1}$. 
the other data. This observation might be related to the phase transition taking place at slightly larger $\mathrm{Al}$ concentrations, which may result in the observed distortion of the lattice.

The structural properties of the thin film were investigated by laterally resolved XRD. These results are shown as a false color plot in Fig. 3(b). Two regions can be distinguished: In the Ga-rich regime (bottom part of the false color image), only peaks related to the (100)-oriented $\beta$-type structure are observed in agreement with our findings for $\left(\operatorname{In}_{x} \mathrm{Ga}_{1-x}\right)_{2} \mathrm{O}_{3} \mathrm{CCS}$ thin films and findings by others for binary $\beta-\mathrm{Ga}_{2} \mathrm{O}_{3} \cdot{ }^{11,15}$ Around $x=0.5$, a phase transition is observed, resulting in only two diffraction peaks in the vicinity of the (600) and (1200) peaks of the $\beta$-phase in the Alrich regime. These can be assigned to the (400) and (800) peaks of $\gamma-\left(\mathrm{Al}_{x} \mathrm{Ga}_{1-x}\right)_{2} \mathrm{O}_{3}$. Diffraction patterns from the respective composition ends are shown in Figs. 3(a) and 3(c).

A non-monotonic behavior of the out-of-plane lattice spacing of the thin film in the $\beta$-phase can already be seen from the composition dependence of the diffraction peaks in the false color plot in Fig. 3. From the peak positions, the out-of-plane lattice distance was calculated as given in Fig. 4(a). It increases with increasing $\mathrm{Al}$ concentration up to $x \approx 0.22$. For higher $\mathrm{Al}$ concentrations, it decreases again as it would be expected from the bulk samples. The relative deviation of the thin film compared to the bulk values for the spacing between [100] planes in dependence on the composition $\left(\Delta d=\left(d_{\text {film }}-d_{\text {bulk }}\right) / d_{\text {bulk }}\right)$ is shown in Fig. 4(b). It increases from closely to zero at $\mathrm{x}=0.11$, similarly to binary $\mathrm{Ga}_{2} \mathrm{O}_{3}$ deposited under equivalent conditions, and increases

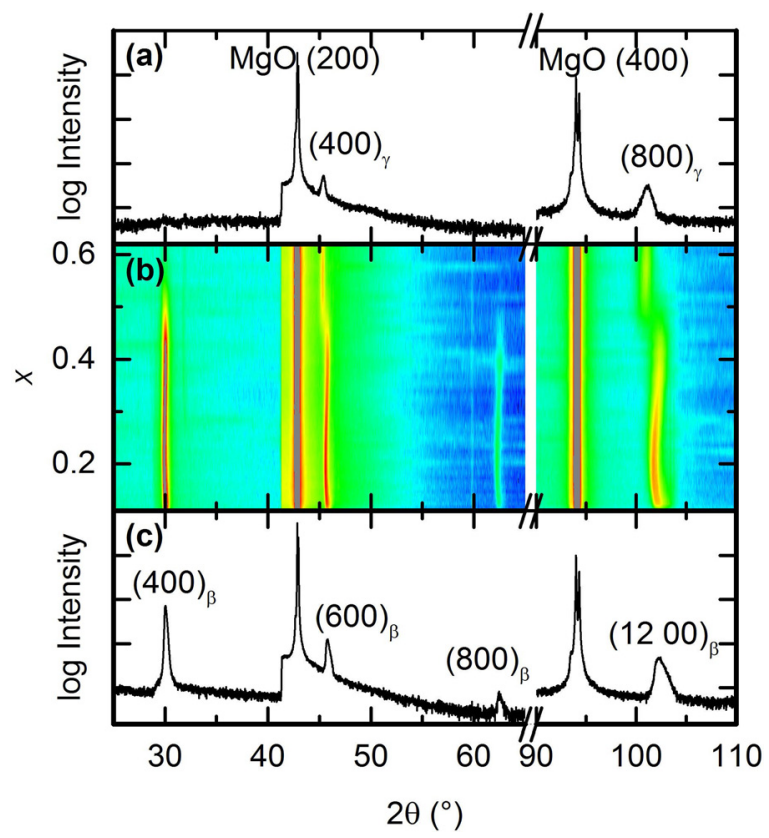

FIG. 3. (b) False color plot of an XRD line scan of the $\left(\mathrm{Al}_{x} \mathrm{Ga}_{1-x}\right)_{2} \mathrm{O}_{3} \mathrm{CCS}$ thin film. The intensity is color-coded on a logarithmic scale from blue (low) to red (high), and grey regions have an intensity above the depicted dynamic range. (a) and (c) Single 2 $\theta-\omega$ scans for the points of the highest and lowest $\mathrm{Al}$ concentration in (b), respectively. The peaks due to $\left(\mathrm{Al}_{x} \mathrm{Ga}_{1-x}\right)_{2} \mathrm{O}_{3}$ are labeled with the respective modification indicated. The steps at $2 \theta \approx 41^{\circ}$ and $90^{\circ}$ are due to the used Ni-filters, which cut the short wavelength Bremsstrahlung below the absorption edge of Ni. No peaks are observed in the full composition range in the break region between $65^{\circ}$ and $90^{\circ}$.

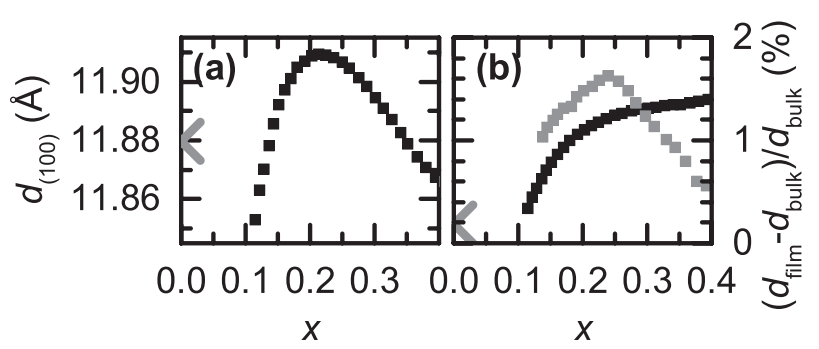

FIG. 4. (a) Out-of-plane lattice spacing determined from the $2 \theta$ - $\omega$-scans of the $\left(\mathrm{Al}_{x} \mathrm{Ga}_{1-x}\right)_{2} \mathrm{O}_{3}$ CCS thin film. (b) Relative deviation of the values from (a) to the bulk values calculated from the linear regression (black) and the equivalent data for the $\left(\operatorname{In}_{x} \mathrm{Ga}_{1-x}\right)_{2} \mathrm{O}_{3}$ thin film grown on $\mathrm{MgO}$ investigated in our previous study ${ }^{11}$ (grey). Values for a binary $\beta-\mathrm{Ga}_{2} \mathrm{O}_{3}$ thin film deposited under equivalent conditions are marked at the $x$-axis by the grey angle.

to a nearly constant value of $\Delta d=1.5 \%$ for large $\mathrm{Al}$ concentrations, corresponding to a similar dependence of the lattice parameter in this composition range as for the bulk samples.

\section{Raman spectroscopy}

The $\beta$-modification of $\mathrm{Ga}_{2} \mathrm{O}_{3}$ has a monoclinic symmetry, which belongs to the space group $C 2 / m / C_{2 h}^{3}$. Its 27 optical phonon modes belong to the irreducible representation ${ }^{16}$

$$
\Gamma^{o p t}=10 A_{g}+5 B_{g}+4 A_{u}+8 B_{u} .
$$

Phonon modes with $A_{g}$ and $B_{g}$ symmetry are Raman active, those with $A_{u}$ and $B_{u}$ symmetry are infrared active.

Raman spectra of the ceramic samples are shown in Fig. 5. For all concentrations shown, the observed Raman peaks match those of the $\beta-\mathrm{Ga}_{2} \mathrm{O}_{3}$ structure. They are labeled according to their symmetry with an additional index in ascending order from low to high energy modes. All samples but the one with the highest $\mathrm{Al}$ concentration were sintered at $T_{2}$. We did not observe any significant differences in the Raman spectra between the samples prepared at different temperatures for $x<0.4$. In this composition range, we further did not find any peaks due to an additional phase for both temperatures. The same is true in the range $0.4<x<0.55$ for the samples sintered at $T_{1}$, but not for those sintered at $T_{2}$ (see below). The small contributions of $\alpha$-phase material found in

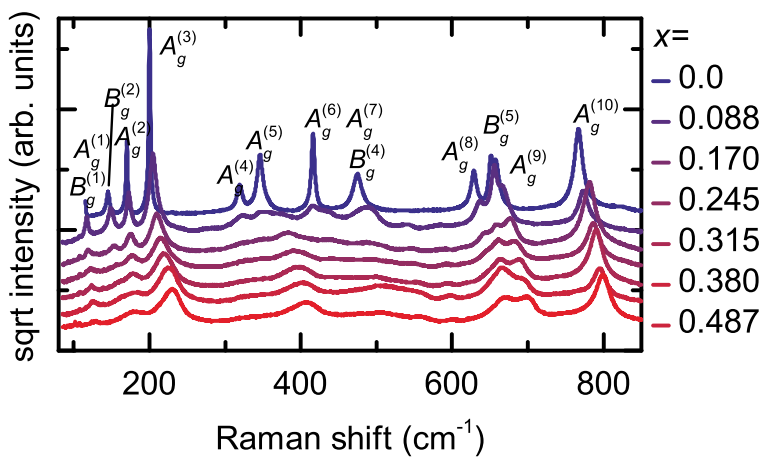

FIG. 5. Raman spectra of $\left(\mathrm{Al}_{x} \mathrm{Ga}_{1-x}\right)_{2} \mathrm{O}_{3}$ ceramic samples with the $\mathrm{Al}$ concentration $x$ given right to the graph, excited at $\lambda_{\text {exc }}=325 \mathrm{~nm}$. Peaks are labeled according to their symmetry. 
TABLE I. Slopes of the energy shift with Al concentration $x$ for several phonon modes of $\left(\mathrm{Al}_{x} \mathrm{Ga}_{1-x}\right)_{2} \mathrm{O}_{3}$. All values given in $\mathrm{cm}^{-1}$, errors are the doubled standard deviations of the linear regression.

\begin{tabular}{lcc}
\hline \hline Mode & $\omega_{0}\left(\mathrm{~cm}^{-1}\right)$ & $\frac{\mathrm{d} \omega}{\mathrm{d} x}$ \\
\hline$A_{g}^{(1)} / B_{g}^{(1)}$ & $111 / 114$ & $31 \pm 2$ \\
$B_{g}^{(2)}$ & 145 & $42 \pm 7$ \\
$A_{g}^{(2)}$ & 170 & $23 \pm 3$ \\
$A_{g}^{(3)}$ & 200 & $64 \pm 7$ \\
$A_{g}^{(7)} / B_{g}^{(4)}$ & 475 & $71 \pm 12$ \\
$A_{g}^{(8)}$ & 629 & $79 \pm 12$ \\
$B_{g}^{(5)}$ & 651 & $37 \pm 4$ \\
$A_{g}^{(9)}$ & 658 & $94 \pm 8$ \\
$A_{g}^{(10)}$ & 767 & $74 \pm 6$ \\
\hline \hline
\end{tabular}

XRD appear to be too weak to be observed in the Raman spectra.

Some of the Raman modes become strongly broadened already for small Al concentrations and, as a consequence, can only be observed in a fraction of the composition range. This is particularly true for the phonon modes in the midspectral range between $300 \mathrm{~cm}^{-1}$ and $500 \mathrm{~cm}^{-1}$. Those modes which can be observed in dependence on the composition show a clear blueshift with increasing Al concentration. We have obtained the composition dependencies of nine Raman peaks by linear regression of the peak positions. These are summarized in Table I. Note that two of these peaks result from scattering by two spectrally close phonon modes with $A_{g}$ and $B_{g}$ symmetry, respectively, which cannot be discriminated by polarization analysis for these polycrystalline samples.

The samples sintered at $T_{2}$ with $x>0.4$ exhibit different Raman spectra depending on the excitation wavelength used. For $\lambda_{\text {exc }}=325 \mathrm{~nm}$, no peaks due to the $\beta$-phase are observed (see Fig. 6(a)). Thus, the respective Raman spectra are assumed to be related to $\gamma-\left(\mathrm{Al}_{x} \mathrm{Ga}_{1-x}\right)_{2} \mathrm{O}_{3}$, which we found from our XRD measurements. Oppositely, excitation at $\lambda_{\text {exc }}=532 \mathrm{~nm}$ yields additional modes due to the $\beta$-phase, in agreement with our findings from XRD (see Fig. 6(b)). These differences are probably related to the absorption of the laser light at $\lambda_{\text {exc }}=325 \mathrm{~nm}$ by the $\gamma$-phase, also causing the bluish color of the samples. Also in this composition range, the Raman modes due to both modifications show a
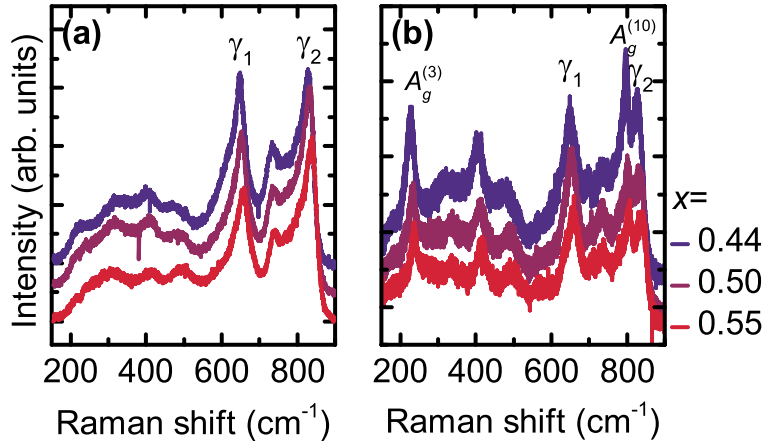

FIG. 6. Raman spectra of $\left(\mathrm{Al}_{x} \mathrm{Ga}_{1-x}\right)_{2} \mathrm{O}_{3}$ ceramic samples with the $\mathrm{Al}$ concentration $x$ given right to the graph, excited at (a) $\lambda_{\text {exc }}=325 \mathrm{~nm}$ and (b) $\lambda_{\text {exc }}=532 \mathrm{~nm}$. Peaks of the $\beta$-phase are labeled according to their symmetry, those of the $\gamma$-phase by $\gamma$.

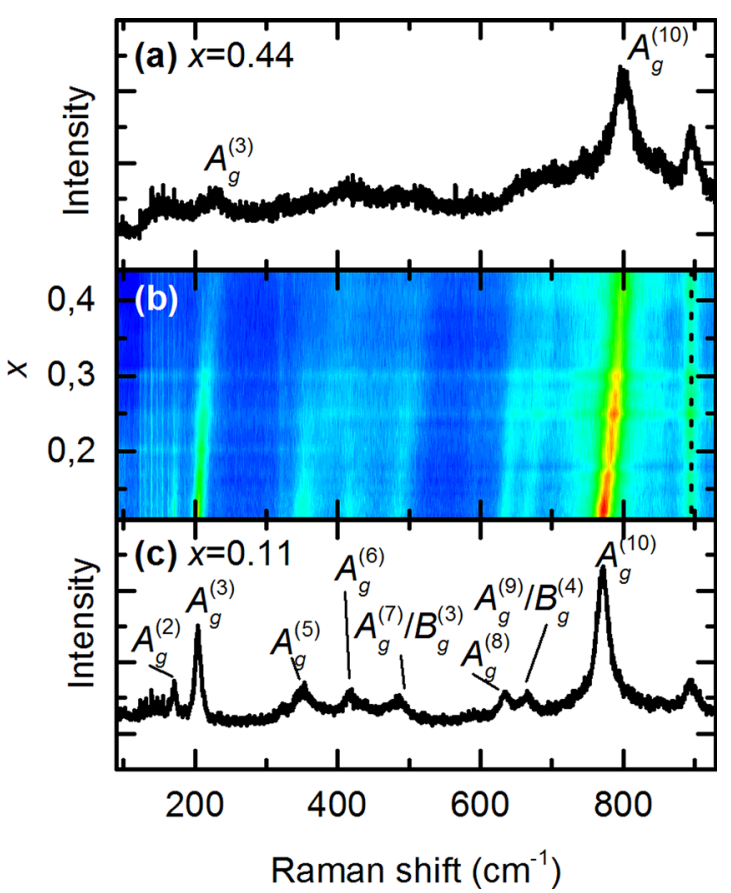

FIG. 7. Raman spectra of the $\left(\mathrm{Al}_{x} \mathrm{Ga}_{1-x}\right)_{2} \mathrm{O}_{3} \mathrm{CCS}$ thin film sample. (b) False color image based on Raman spectra measured at 28 positions with different Al concentrations. The intensity is color-coded from blue (low) to red (high). The vertical dotted line indicates a multi-phonon mode from the $\mathrm{MgO}$ substrate. (a) and (c) The spectra from the points of highest and lowest $\mathrm{Al}$ concentration of $(\mathrm{b})$, respectively.

blueshift with increasing $\mathrm{Al}$ concentration. Despite the occurrence of the $\gamma$-phase, the phonon energies of the observable $\beta-\left(\mathrm{Al}_{x} \mathrm{Ga}_{1-x}\right)_{2} \mathrm{O}_{3}$ Raman modes are in agreement to the composition dependencies of Table I.

Spectra for the CCS thin film are shown in Fig. 7 for $0.11<x<0.44$ by means of a false color image, together with spectra at the respective composition ends. A monotonic shift of the $\beta-\mathrm{Ga}_{2} \mathrm{O}_{3}$ phonon modes can be observed without the splitting of any modes. Also, no additional peaks appear. Thus, the phonon modes of this alloy show a onemode behavior similar to $\left(\operatorname{In}_{x} \mathrm{Ga}_{1-x}\right)_{2} \mathrm{O}_{3}{ }^{11}$ and no secondary phase could be detected in this composition range. For higher Al concentrations, the Raman spectrum vanishes. Neither modes due to $\beta$ - nor $\gamma-\left(\mathrm{Al}_{x} \mathrm{Ga}_{1-x}\right)_{2} \mathrm{O}_{3}$ can be observed for $x>0.5$. The Raman scattering cross section of $\gamma-\left(\mathrm{Al}_{x} \mathrm{Ga}_{1-x}\right)_{2} \mathrm{O}_{3}$ appears to be too weak to be measured for these thin film samples.

The spectral positions of the observed peaks in dependence on the composition are depicted in Fig. 8 (black squares) together with the data for the ceramic samples (triangles). The mode in Fig. 8(c) cannot be unambiguously assigned to one of the modes $A_{g}^{(9)}$ or $B_{g}^{(4)}$ from its intercept with the energy axis. However, its composition dependence allows to identify it as the $A_{g}^{(9)}$ mode. All of these modes show a slope similar to the data for the bulk samples. The absolute energies are redshifted slightly (by $1-2 \mathrm{~cm}^{-1}$ ) for the thin film. This is similarly observed for the binary $\beta$ $\mathrm{Ga}_{2} \mathrm{O}_{3}$ thin film. Small deviations from the linear behavior are observed only for some modes of the thin film. This is particularly pronounced for the $A_{g}^{(10)}$ mode, which deviates from the bulk values particularly for low $\mathrm{Al}$ content. 

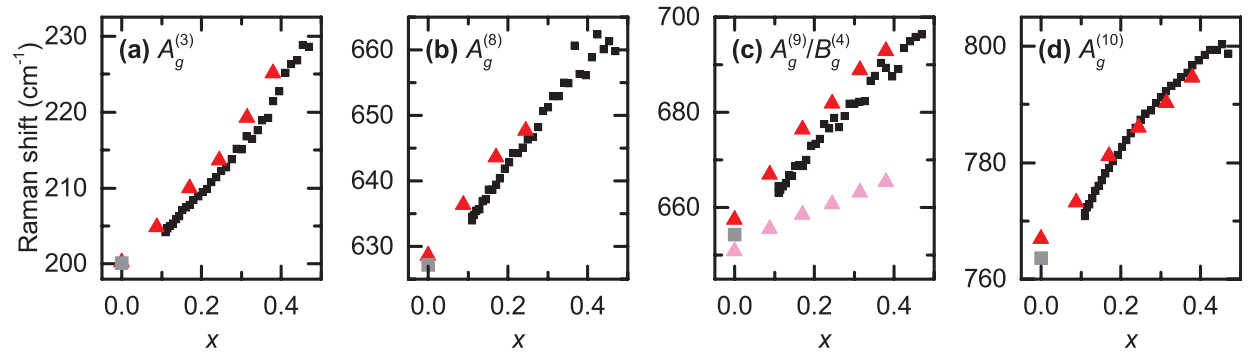

FIG. 8. (a)-(d) Peak energies of four different phonon modes in dependence on the indium concentration in the sample. Data for the ceramic samples are represented by red triangles, data for the CCS film by black squares, and data for a binary $\beta-\mathrm{Ga}_{2} \mathrm{O}_{3}$ film deposited under similar conditions by grey squares. In (c), the red and pink triangles represent the data points for the $A_{g}^{(9)}$ and $B_{g}^{(4)}$ mode, respectively.

\section{DISCUSSION}

We found lower solubility limits of $\mathrm{Al}$ in the $\beta-\left(\mathrm{Al}_{x} \mathrm{Ga}_{1-x}\right)_{2} \mathrm{O}_{3}$ lattice for our ceramic samples for both sample preparation temperatures. While we found additional phases for all samples with $x>0.4$, a full solid solution of the $\mathrm{Al}$ in the $\beta-\mathrm{Ga}_{2} \mathrm{O}_{3}$ lattice was found previously for $x<0.8$ under similar preparation conditions. ${ }^{7-9}$ The reason for that remains unclear.

The observed occurrence of the $\gamma$-modification for sintering at $T_{2}$ is in contradiction to reports in the literature ${ }^{7-9}$ as well. In these reports, a phase transition to the $\alpha$-modification was found. However, the addition of only a small amount of $\mathrm{MgO}$ also yielded the here observed $\gamma$-phase. ${ }^{9}$ Thus, the formation of the $\gamma$-phase appears to be only slightly less favorable than the other phases. More research is required to determine why the $\gamma$-phase appears in our samples, but this is out of the scope of this manuscript and may be subject of future studies.

The dependencies of all individual lattice parameters on the $\mathrm{Al}$ concentration have not been published before. Stalder and Nitsch ${ }^{9}$ reported data for the lattice parameters $a$ and $c$ (Please note that in Ref. 9 the notation is switched with respect to the commonly used one). These show a strong deviation from the values we found here, particularly a much stronger composition dependence. However, for several reasons, our data appear more reliable. In that publication, ${ }^{9}$ the extrapolation for $x=0$ is $2 \%-3 \%$ off the literature values for binary $\beta-\mathrm{Ga}_{2} \mathrm{O}_{3},{ }^{17}$ while our values are within an error margin of $\pm 0.2 \%$. Further, the relative change of the lattice spacings obtained by Hill et al. ${ }^{7}$ is in good agreement to the relative change of the lattice parameters found by us. Similarly, the unit cell volume, which can be calculated from the lattice parameters obtained by us, shows a good agreement to previously published data. ${ }^{8}$ In comparison to $\left(\mathrm{In}_{x} \mathrm{Ga}_{1-x}\right)_{2} \mathrm{O}_{3}$, the lattice parameters show a less pronounced dependence on the composition. ${ }^{11}$ This relates well to the ionic radii of the involved elements: The difference between the ionic radii of $\mathrm{Al}(0.675 \AA)$ and $\mathrm{Ga}(0.76 \AA)$ is notably smaller than that between $\mathrm{Ga}$ and In $(0.94 \AA) .{ }^{18}$

No data from literature on the phonon modes of $\left(\mathrm{Al}_{x} \mathrm{Ga}_{1-x}\right)_{2} \mathrm{O}_{3}$ is available for comparison. The modes which we observed in the ceramic samples over a broad composition range show a linear dependence of their energy on the $\mathrm{Al}$ content, similar to our findings for $\left(\operatorname{In}_{x} \mathrm{Ga}_{1-x}\right)_{2} \mathrm{O}_{3}{ }^{11}$

The out-of-plane lattice spacing of the thin film is significantly larger than the bulk values. The deviation is similar to our findings for PLD-grown $\left(\operatorname{In}_{x} \mathrm{Ga}_{1-x}\right)_{2} \mathrm{O}_{3}$ on $\mathrm{MgO}$ (Ref. 11) (cf. Fig. 4(b)). For small $x$, it increases with increasing $x$ for both compounds. If it would result from strain induced by the lattice mismatch to the substrate, an opposed behavior would be expected since the in-plane lattice mismatch is reduced for one and increased for the other compound for increasing $x$. Thus, the observed behavior cannot be explained by strain induced by a lattice mismatch to the substrate. That explanation would also seem unreasonable regarding the large magnitude of the lattice mismatch of around 2\% (Ref. 15) in combination with the film thickness of around $500 \mathrm{~nm}$. For binary $\beta-\mathrm{Ga}_{2} \mathrm{O}_{3}$ thin films deposited under equivalent conditions, we find a good agreement of the out-of-plane lattice spacing to the bulk value. Thus, we suppose that internal strain induced by defects and disorder, which become more significant for increasing $x$, are responsible for the observed deviations.

Despite the strong deviation in the lattice plane spacing relative to the bulk values, we found a good agreement for the phonon energies. A small shift of the phonon energies towards lower values relative to the bulk samples is observed, particularly for low $\mathrm{Al}$ concentration. This is, however, in agreement with our results for binary $\mathrm{Ga}_{2} \mathrm{O}_{3}$ thin films, which exhibit a similar deviation. The reason for this appears to be connected to the growth conditions: The phonon energies of thin films can be increased by using a higher oxygen pressure during deposition, resulting in values close to the bulk values for a pressure of 0.016 mbar. Particularly, the $A_{g}^{(10)}$ mode also shows some deviation from the linear behavior of the bulk phonon energies, probably related to a more pronounced sensitivity of this mode to the internal strain in the samples. A reason for the different sensitivities of the individual phonon modes to strain properties cannot be given at this point. However, according to our observations, the determination of the $\mathrm{Al}$ concentration in $\beta-\left(\mathrm{Al}_{x} \mathrm{Ga}_{1-x}\right)_{2} \mathrm{O}_{3}$ using Raman spectroscopy appears to be possible with reasonable accuracy also for non-ideal thin films, but the error of this method is somewhat larger than for $\left(\operatorname{In}_{x} \mathrm{Ga}_{1-x}\right)_{2} \mathrm{O}_{3}{ }^{11}$ This might be particularly interesting for the investigation of thin films grown on $\mathrm{Al}_{2} \mathrm{O}_{3}$ substrates, for which the determination of the $\mathrm{Al}$ content is not possible from EDX owing to the aluminum in the substrate.

\section{CONCLUSIONS}

We have determined the lattice parameters for the $\left(\mathrm{Al}_{x} \mathrm{Ga}_{1-x}\right)_{2} \mathrm{O}_{3}$ ternary compound in dependence on the 
composition. The linear relations of nine Raman peaks on the $\mathrm{Al}$ concentration incorporated in the $\beta-\mathrm{Ga}_{2} \mathrm{O}_{3}$ host lattice were determined with high accuracy from ceramic samples. Although the composition-dependent lattice spacings of our CCS thin films show a deviation from the ideal material, the phonon modes of the film exhibit essentially the same trend as those of the ceramic samples. We found a smaller solubility limit of $\mathrm{Al}$ in the $\beta-\mathrm{Ga}_{2} \mathrm{O}_{3}$ lattice than reported before of about $x<0.4$ for the ceramic samples. The additional phase forming for higher $\mathrm{Al}$ concentration depends on the applied preparation temperature. We observed the formation of the $\alpha$-phase for sintering at $1400^{\circ} \mathrm{C}$ and of the $\gamma$-phase for sintering at $1550{ }^{\circ} \mathrm{C}$. The PLD-grown films exhibited a phase transition from the $\beta$ - to the $\gamma$-modification at $x \approx 0.5$.

\section{ACKNOWLEDGMENTS}

C.K. was funded by the European Union and the Free State of Saxony. This work was supported within the framework of EFRE (SAB 100132251). We would like to thank Daniel Splith for valuable discussions, Gabriele Ramm for the preparation of the PLD targets and ceramic samples, Holger Hochmuth for thin film growth, and Michael Bonholzer for additional XRD measurements.
${ }^{1}$ M. Higashiwaki, K. Sasaki, A. Kuramata, T. Masui, and S. Yamakoshi, Appl. Phys. Lett. 100, 013504 (2012).

${ }^{2}$ T. Oshima, T. Okuno, N. Arai, N. Suzuki, S. Ohira, and S. Fujita, Appl. Phys. Express 1, 011202 (2008).

${ }^{3}$ T. Oshima, T. Okuno, and S. Fujita, Jpn. J. Appl. Phys., Part 146, 7217 (2007).

${ }^{4}$ Y. Kokubun, K. Miura, F. Endo, and S. Nakagomi, Appl. Phys. Lett. 90, 031912 (2007).

${ }^{5}$ H. von Wenckstern, D. Splith, M. Purfürst, Z. Zhang, C. Kranert, S. Müller, M. Lorenz, and M. Grundmann, Semicond. Sci. Technol. 30, 024005 (2015).

${ }^{6}$ H. von Wartenberg and H. J. Reusch, Z. Anorg. Allg. Chem. 207, 1 (1932).

${ }^{7}$ V. G. Hill, R. Roy, and E. F. Osborn, J. Am. Ceram. Soc. 35, 135 (1952).

${ }^{8}$ A. L. Jaromin and D. D. Edwards, J. Am. Ceram. Soc. 88, 2573 (2005).

${ }^{9}$ R. Stalder and K.-H. Nitsch, J. Am. Ceram. Soc. 80, 258 (1997).

${ }^{10}$ T. Oshima, T. Okuno, N. Arai, Y. Kobayashi, and S. Fujita, Jpn. J. Appl. Phys., Part 1 48, 070202 (2009).

${ }^{11}$ C. Kranert, J. Lenzner, M. Jenderka, M. Lorenz, H. von Wenckstern, R. Schmidt-Grund, and M. Grundmann, J. Appl. Phys. 116, 013505 (2014).

${ }^{12}$ H. von Wenckstern, Z. Zhang, F. Schmidt, J. Lenzner, H. Hochmuth, and M. Grundmann, CrystEngComm 15, 10020 (2013).

${ }^{13}$ H. M. Rietveld, Acta Crystallogr. 22, 151 (1967).

${ }^{14}$ D. Dohy and J. Gavarri, J. Solid State Chem. 49, 107 (1983).

${ }^{15}$ L. Kong, J. Ma, C. Luan, W. Mi, and Y. Lv, Thin Solid Films 520, 4270 (2012).

${ }^{16}$ D. Dohy, G. Lucazeau, and A. Revcolevschi, J. Solid State Chem. 45, 180 (1982).

${ }^{17}$ J. Åhman, G. Svensson, and J. Albertsson, Acta Crystallogr. C 52, 1336 (1996).

${ }^{18}$ R. D. Shannon, Acta Crystallogr. A 32, 751 (1976). 